\title{
The cow in the room
}

\author{
Our food system reflects and affects our values. Recognizing and understanding the power of those often unstated \\ value systems is critical for avoiding a range of disasters.
}

M any consider themselves to have a right to a sound environment (see the Q\&A in this issue of Nature Sustainability) as well as to a car on demand (as described in an Article by Joanna Moody and colleagues also in this issue) and a steak on their plate (see Brief Communication by Richard York). The convening of the United Nation's Food Systems Summit 2021 on 23 September is a good time to reflect on this reality, both for food and more broadly. The Summit's worthwhile goal is to "deliver progress on all 17 of the SDGs [Sustainable Development Goals] through a food systems approach, leveraging the interconnectedness of food systems to global challenges such as hunger, climate change, poverty and inequality."

A growing chorus of studies, books and blogs have been written about the systemic nature of our food issues, and for good reason. Like other systems, our food system is composed of different entities and actors - from crops to producers and consumers to corporations - linked locally and globally whose interactions produce emergent and sometimes surprising outcomes. For example, two studies in this issue - see Article by Stefan Bringezu and colleagues and Article by Xiao-Peng Song and colleagues - showcase the degree to which animal agriculture, mostly for cattle, drives land use and change elsewhere and our broader agricultural footprint. The Summit considers recognizing such complexity key to a strong food system and food systems as linked to all 17 Sustainable Development Goals. We agree. At the broadest level, too, the structure and function of food systems relative to the constraints of the planet reflects their potential sustainability.

Our values and expectations around food, transport and other factors constitute systems as well. The notion of individual value systems is commonplace, but how they affect our choices is not always as obvious. For individuals, food is expensive but dwarfed by the cost of car ownership when that is even an option. In an enlightening twist, Moody and colleagues find that among residents of four major US metro areas, the value of owning a car is driven more by non-use considerations, such as the option to travel when necessary and the status involved,

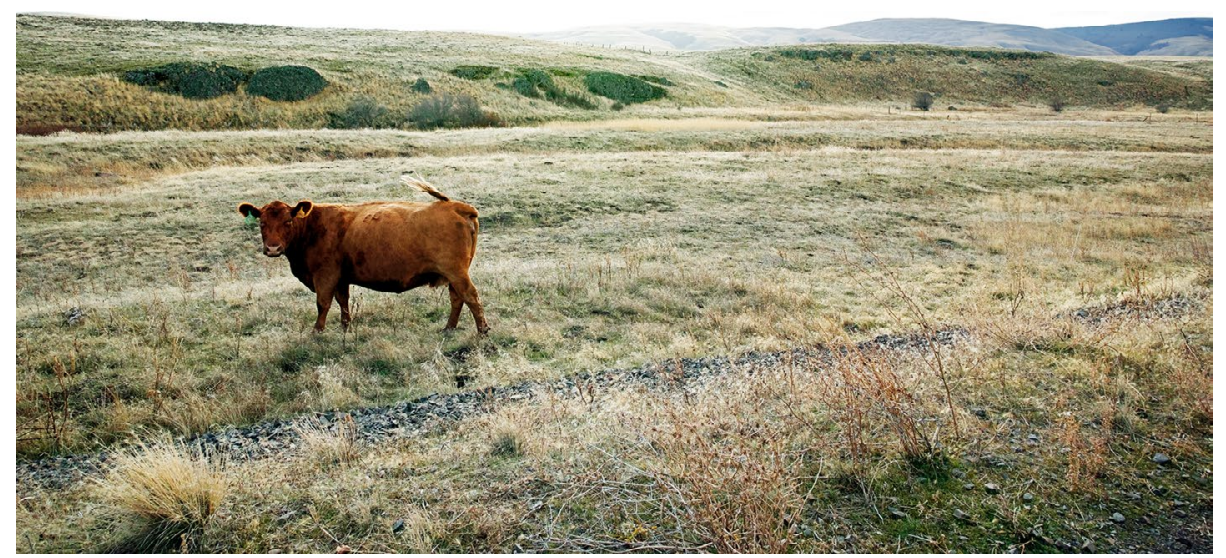

Credit: jhillphotography/Moment/Getty

than by "the use value of getting from $A$ to B.” However expensive, a car's perceived value matches or exceeds its financial cost. Options matter, as does status. But as York finds, options beyond beef and pork did not decrease, or displace, consumption of them globally between 1961-2013. Rather, greater consumption of poultry, fish and aquatic invertebrates was part of a rising tide of animal consumption generally. As with cars, people value options and status in food choices, though broader social norms and other considerations matter as well in shifting diets (S. Eker, G. Reese and M. Obersteiner, Nat. Sustain. 2, 725-735; 2019). For food and for cars, individual value systems are surely influenced by broader networks, including transport networks used by cars and social networks affecting perceived status.

Just as ecosystems can reduce disaster risks (see Analysis by K. Sudmeier-Rieux and colleagues in this issue), so can our value systems. We are confronted daily with the evidence. On the ecosystem front, mangrove ecosystems are renowned for helping attenuate waves and reduce risks from coastal storms. Intact forest and grassland ecosystems stabilize slopes and reduce risks of landslides after heavy rains. On the value-system front, pandemic brush fires reflect values about vaccination and masking, while wildfires indirectly reflect values over time about wildland management and greenhouse-gas-producing activity.
As with all complex systems, our value systems are diverse and evolving, both within individuals and within larger entities, from families to communities and from local governments to the United Nations. Some of these values we share broadly, and on others we diverge. Understanding how values are linked and scale, though, will help us all grapple with how to make food systems more just, inclusive and diverse while being less resource intensive and environmentally destructive. Information alone - knowing what the problem is and even what is driving it - is rarely enough, as studies on climate denialism have shown.

Imagine a room of your values and those of groups to which you belong. What would populate that room? If it contained a cow, would you see it? You may value private combustion-driven transportation. Cow, welcome car. The room is getting crowded, though some might argue the room's size is not fixed. The notion that our planet is crowded has been around, if debated, a long time (Nat. Sustain. $2,1 ; 2019)$. What about the crowding and conflicts of our values, ideals and aspirations? How can we understand them in relation to food systems and others? We welcome research and opinion on these ideas and on this frontier. After all, so much is at steak.

Published online: 17 September 2021 https://doi.org/10.1038/s41893-021-00776-6 